\title{
Business and Disruptive Innovation in Philosophy of Technology and Innovation Support Center
}

\author{
Raden Arum Setia Priadi ${ }^{1}$, Andani Achmad ${ }^{2}$, Ansar Suyuti $^{3}$ \\ \{rasp@eng.unila.ac.id ${ }^{1}$, andani60@yahoo.com ${ }^{2}$, ansarsuyuti@gmail.com ${ }^{3}$ \} \\ Electrical Engineering Hasanuddin University ${ }^{123}$
}

\begin{abstract}
Abstract contains research problem, The problem arose when there were only a few universities as a place to gather all inventors, designers, and creators who had intellectual property centers. Of the not many Intellectual Property Centers, fewer have implemented Technology and Innovation Support Centers with a legal umbrella of memorandum of understanding with the Directorate General of Intellectual Property, Ministry of Law and Human Rights of the Republic of Indonesia. Aims of the study, This study seeks to map the problems and current conditions of 17 universities that have implemented the Technology and Innovation Support Center. The picture sought is focus on information technology infrastructure in the form of a computer system that has been built by the 17 leaders of the university. A classification of the quality of the computer system and boosting method will be made that makes it easy for beginner colleges in intellectual property affairs to adopt its Intellectual Property Center and Technology and Innovation Support Center. Research method, Large amounts of data include intellectual property data managed by Intellectual Property Centers in all forms and levels. The data is obtained from all inventors, designers, and creators it serves. Improvement of service quality can be obtained by installing the Technology and Innovation Support Center, which was initiated by the World Intellectual Property Organization. Data science is the extraction of knowledge from large volumes of structured or unstructured data which is a continuation of mining field data and predictive analysis, also known as knowledge discovery and data mining. Results, The presence of informatics philosophers is needed so that the stakeholders' understanding will occur in order to handle business and disruptive innovation using technology and innovation support centers. And recommendation, Recommended to the Directorate General of Intellectual Property, the Indonesian Intellectual Property Center Association, and the Directorate General of Innovation Strengthening to meet in order to form a shared philosophy regarding technology and innovation support centers.
\end{abstract}

Keywords: Philosophy; TISC; business; disruptive

\section{Introduction}

Details of background (research significance): The dissertation research /research field is planned to focus on the topic/theme of research, namely research challenge on the development of internet-based data science systems with cloud computing technology and virtualization in the form of Technology and Innovation Support Centers (TISC), namely: program schemes that provide innovators /inventors in countries developing countries with local resource-based access, high-quality information technology and related services as 
needed, help them to exploit their innovative potential and create, protect and regulate their intellectual property.

Formulation of problems /questions (preliminary research): Computer-based systems that are examined are the Technology and Innovation Support Center (TISC). The World Intellectual Property Organization mandates that in each country there is one government agency that takes care of the institution, in the context of Indonesia, the agency intended is the Directorate General of Intellectual Property. The related problem can be formulated here is how is a comprehensive review of data science with big data keywords, data analysis, data analytics, from many Indonesian universities that have built the institution can facilitate the needs of the Intellectual Property Center? How is the sustainable development knowledge platform suitable (for each regional Indonesian university, for example, each specific island: Sumatra, Java, Sulawesi, Kalimantan, Papua) facing business and disruptive innovation?

Theory and related work (journal review): Which is considered good and which is considered bad (ethics)? There are intellectual property ethics from Tech Terms, Media Smarts, Titania, Investopedia. Ethics is a set of moral principles governing the habit of a group or individual. So computer ethics can be interpreted the moral rules that manage computer use. Some common issues include intellectual property rights (such as electronic content copyrights), privacy matters, and how do computers affect society? (Ethics and Intellectual Property n.d.). Theory and related work (journal review): Computer-Based Information System (CBIS) refers to information systems developed based on computer technology. The term comes from a book entitled Analysis \& Design of Information Systems for Competitive Advantages of Companies \& Modern Organizations, by Hanif Al Fatta, STMIK AMIKOM Yogyakarta. The formulation is known as follows (Fatta 2007):

CBIS $=$ hardware + software + stake holder + procedure + information

The complex system where the computer plays the main role consists of physical system and software system can help people live healthier and favors. Failure of this system can result in disaster loss of money, time, and life (example of Bank Mandiri case). The complexity of this system relates to the integration of information technology into physical and human activities. Integration dramatically increases interdependence among components, people, and processes, generating complex dynamics. Engineers with a detailed understanding of the application domain and electronics computer, software, human factors, and communication are needed to provide holistic approach to system development so that disaster can be avoided. (White 2014)

Hypothesis (optional), and research objectives (short term)? Hypothesis (optional): Details of the philosophy of informatics science can be built which is proposed to improve the reliability of TISC implementation through several ways to obtain knowledge of data science from a collection of IPR information data so that knowledge is useful for facilitating inventors, creators, designers, and their families and society in general. Research objectives (short term): In the context of electrical engineering, philosophy can be interpreted as a friend / friend of wisdom in solving life problems, examples of Gojek and Grab applications solve the problems of motorcycle taxi drivers. Dissertation Context, Philosophy Is A Friend / Friend Of Friends In Completing Data Science Problems In Technology And Innovation Support Center (Tisc).

Since the appearance of the computer, the system, innovation has been greatly helped. Many inventors are facilitated by the invasion process, which can help the beneficiaries of their discoveries, for example vehicles (land, sea, air), are called disruptive innovation, which is innovation that helps. In business theory, disruptive innovation is innovation that creates 
new markets and valuable networks. All of this can be related to the business at the IPR Office that manages intellectual property in the form of innovations that need to be created with a valuable market network so as to bring benefits to all stakeholders.

\section{Methods}

Detailed time and research context can be arranged in a fish bone diagram. Data collection and translation methods use search engines and translators such as Google.com, Bing.com, Yahoo.com, Translate.com, PROMT-Online, Babylon NG. Social media is also used to find out the response of netizens like Facebook.com, Twitter.com, Instagram.com, LINE.me. All material is arranged on a computer using Mendeley Desktop. The analytical method uses philosophical science material.

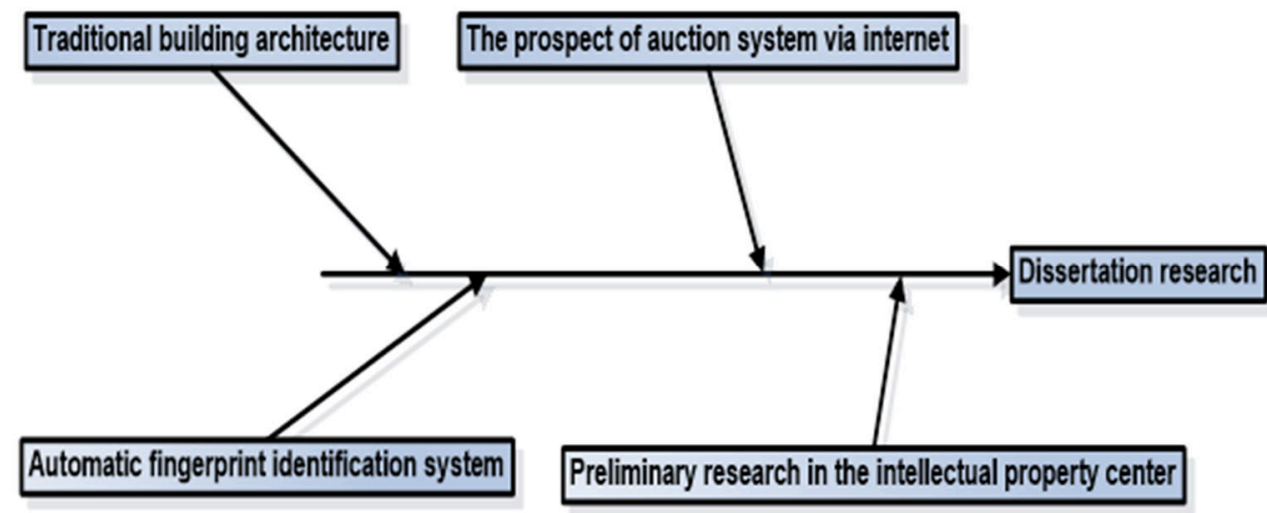

Fig 1. Fish bone diagram from the research experience of the author.

Fish bone diagrams or also called cause and effect diagrams are arranged starting from the first time the author conducted research writing from school to college. The experience of researching gives wisdom in the form of the need for us to know the architecture of the philosophy of informatics first. After that, it is necessary to think about the identification system automatically to facilitate the process of introducing TISC stake holders. To facilitate the parties' transaction process, an auction mechanism needs to be considered to access the resources and products needed. Early research is needed to map problems in the intellectual property center. All the processes support dissertation research to develop data science in TISC.

\section{Results and Discussion}

Result and Discussion presents and analyses the findings thoroughly. Describe in this section the research findings clearly. The philosophy of informatics can be explained by the following pictures: 


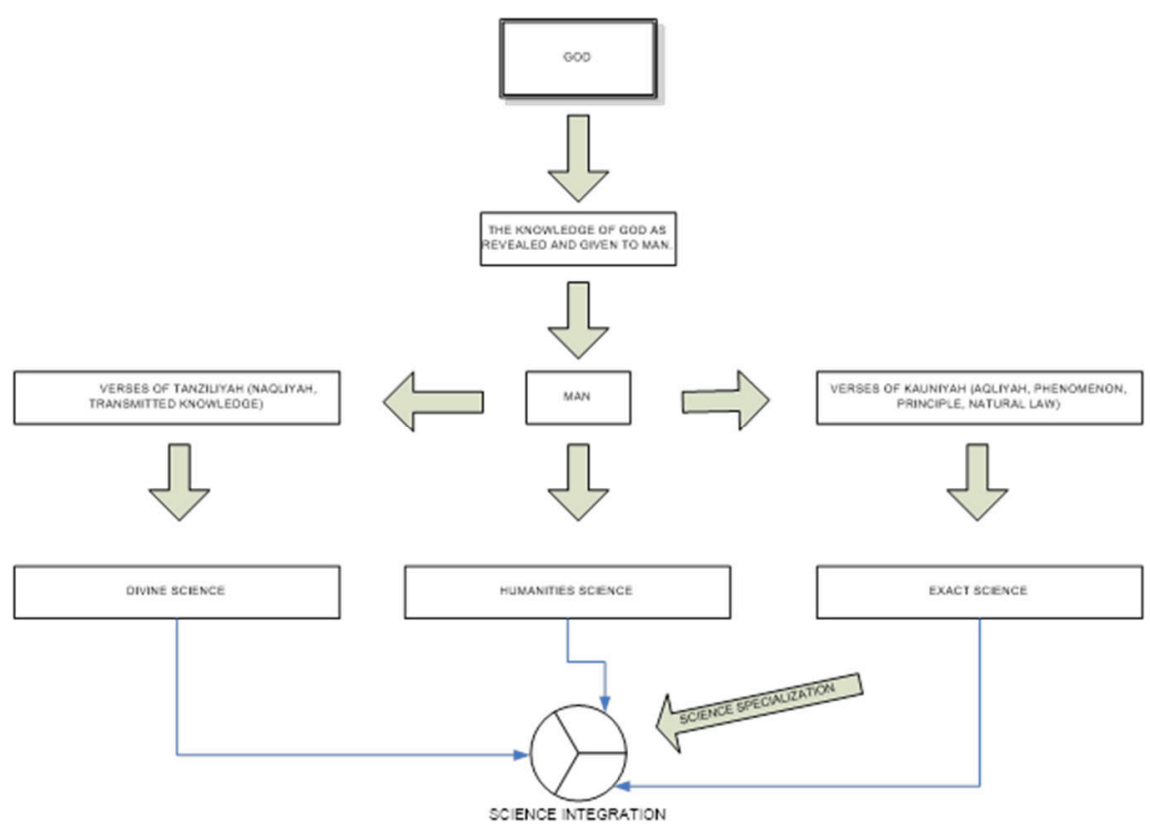

Fig 2. The philosophy of informatics can be traced from the kauniyah verses to science / exact to the plate of science integration, aiming at specialization in informatics. So with the philosophy of science can be integrated the science of divinity and science / exact. (Mustopo 2017)

Seen in the picture that the humanities / social sciences are also mixed in the dish. This is in accordance with the fact that users of informatics are human beings or groups of people that need to be studied as well. So like that disc, TISC can soon be established after a complete philosophy of informatics science with moral principles compiled to provide guidance for the recruitment of some experts who develop useful data science for communities that Care by IPR Office.

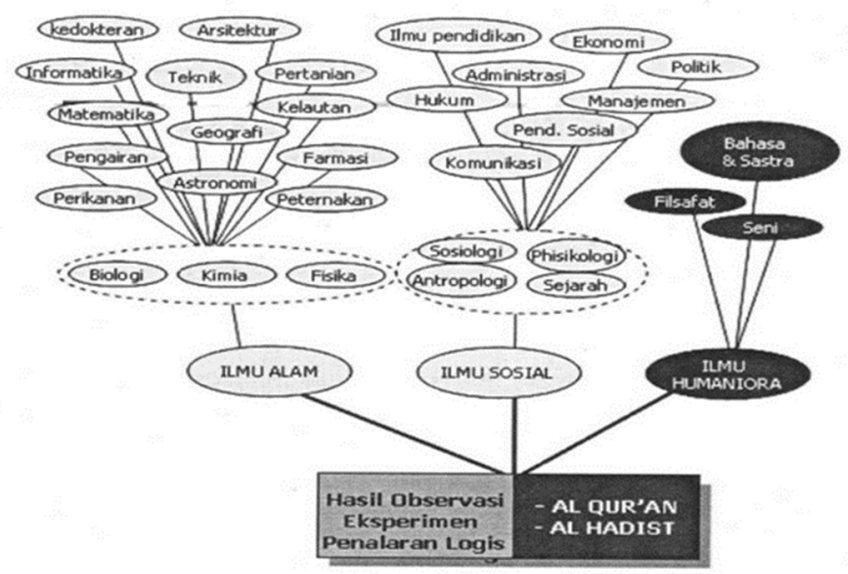


Fig 3. Informatics is grown from natural sciences with three main constituents namely biology (humans who studied ergonomics), chemistry (composition of composing materials of computers as the main tools of informatics), physics (physical computer materials and electrical phenomena), [please use Google Translate /Bing Translator].

At the level of doctoral programs, the philosophy of science must be studied before embarking on a series of in-depth and detailed research because researchers are human beings as well as philosophies which enable the incorporation of divine science, humanities, and science / exact.
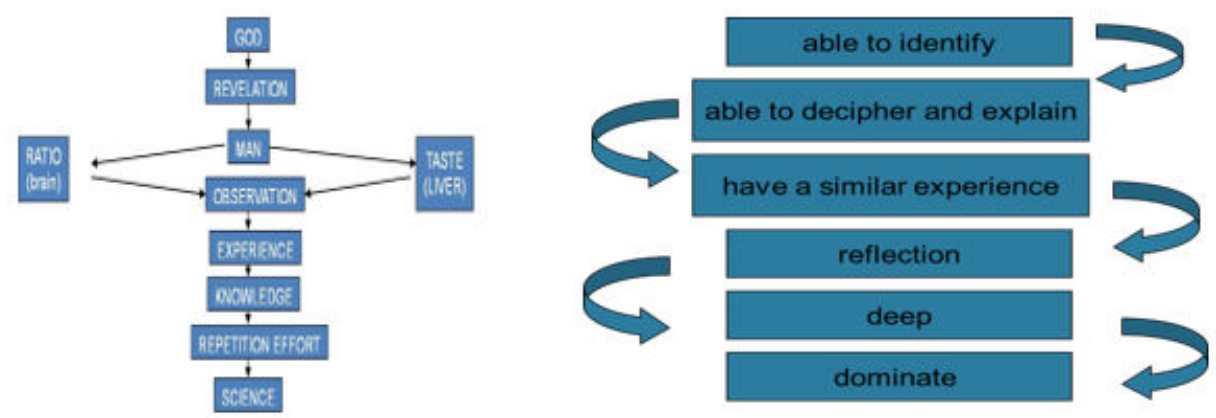

Fig 4. Part a (left) shows how philosophy recognizes the source of knowledge, namely God and describes the process of the occurrence of knowledge that results in business innovations and innovations that create new markets, disrupt or damage existing markets. Part b (right) states the process of knowing objects, namely business \& disruptive innovation, starts from the ability to identify problems that require innovation to master the new market. (Achmad 2019)

Knowledge as a capital in innovating, has been demonstrated by part-A, as the process of occurrence. Knowledge that accumulates into science. With knowledge, innovators are able to do many things on the B. resulting in a business and disruptive innovation.

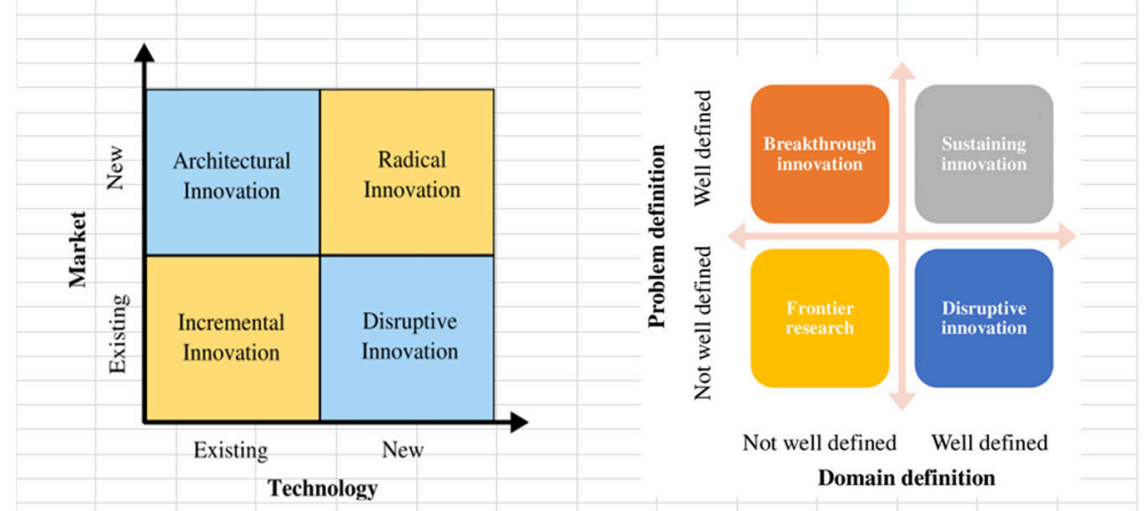

Fig 5. Seen in part a (left), disruptive innovation has applied new technology to existing markets, causing disruption to existing business people. (Lopez 2015) Seen in section b (right), disruptive innovation has defined the domain well even though the definition of the problem has not been done well. (Kristóf 2016) 
Can be modeled here innovations such as Gojek, Grab, and Uber. All these applications interfere with base Ojek which eventually gets eliminated. Even Uber was eliminated for the Indonesian case. All the applications interfere with the Ojek market already in many bases. They have not been resolved to define the problems faced even though the domain definition is final is the driver Ojek and car. Another case is an intermediary trading business or a realtor. Now with the innovation of the Internet market place, many middlemen traders are on the mat because the end users directly buy directly to the manufacturer. It also improves the business of freight delivery services. The latest case is the learning guidance Business (Bimbel) has transformed into an online world such as RuangGuru that just celebrated its existence for five years in Indonesia. This significantly spits a private bimbel. Only the major Bimbel businesses still remain in the world of education.

Here is the significance of the Indonesian Intellectual Property Center Association (ASKII) which needs to develop technology and innovation support centers (TISC). The shareholders of all disruptive innovation applications that develop their business innovations need to contact ASKII and the closest university to the head office and branch offices of the company to resolve the problem definitions that are always emerging. Usually, business innovations have a parent company that operates as a global Multi National Corporation, able to solve macro problems but fail to solve the micro problems faced by its stakeholders, especially Ojek drivers and cars even though they already have Internet devices and social media devices.

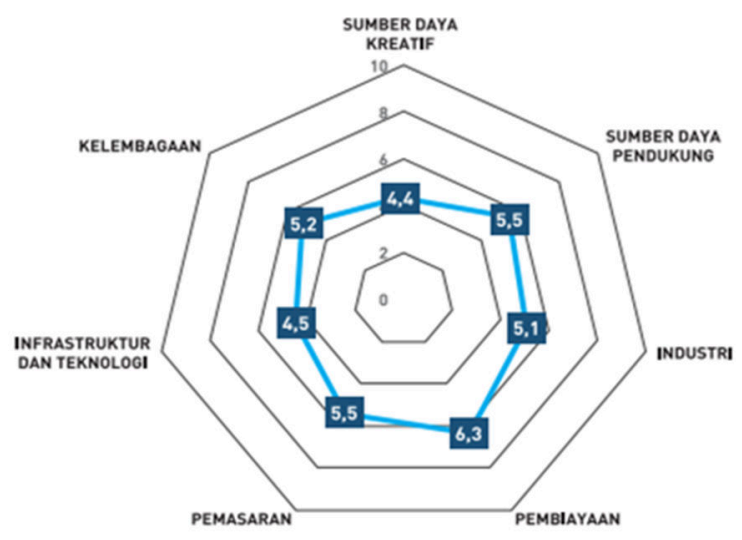

Fig 6. Mapping of Industry Competitiveness as shown in this figure needs to be done regularly by industry shareholders from business and disruptive innovation. This can be made possible by cooperating with technology and innovation support centers (TISC) that may exist in every intellectual property center.

TISC is assisting IPR Offices in transforming the registered intellectual property into a business and disruption innovation that is beneficial to the intellectual property community. For each business that TISC developed need to develop measuring instrument to create Mapping of Industry Competitiveness periodically for example annually. Unfortunately it is still limited to the concept that WIPO developed, not really applied especially by 17 colleges that have signed memorandum of Understanding with the Directorate General of Intellectual Property. It is evidenced that there is not a single TISC Indonesia registered in the WIPO Directory. Still happening in the DJKI level, there is confusion at the level of intellectual property centers of many universities. It is a sign of the unexplained philosophy that is held to develop all that. 


\section{Conclusion and Recommendation}

Because of the lack of universities with the necessary organ that is the center of intellectual property that develops technology and innovation Support Center (TISC), many industries that are listed in many companies need to coordinate with the science and techno Park which corresponds to the area of the line and nearest to the head office and branch of the company. Colleges with doctoral program students will certainly start work by formulating a philosophy of science related to their fields of work if they get assignments in intellectual property centers that develop technology and innovation support centers (TISC). Focus on each study program, student Doctor program can develop informatics science philosophy from business and disruptive innovation with Computer-Based Information System refers to information systems developed Based on Computer technology. Higher education levels should be centered in the technology and Innovation Support Center.

\section{References}

[1] Achmad, Andani. "Materi Kuliah Filsafat Ilmu." Makassar, Sulawesi Selatan, 2019.

[2] Ethics and Intellectual Property. n.d. http://mediasmarts.ca/digital-media-literacy/digitalissues/online-ethics/ethics-intellectual-property (accessed 6 14, 2019).

[3] Fatta, Al Hanif. Analisis \& Perancangan Sistem Informasi untuk Keunggulan Bersaing Perusahaan \& Organisasi Modern. Yogyakarta: Penerbit ANDI, 2007.

[4] Kristóf, Péter. "How established companies can master disruptive innovation like startups? Achieving innovation excellence and disruptive ability." ResearchGate. June 2016. https://www.researchgate.net/publication/307560120_How_established_companies_can_maste r_disruptive_innovation_like_startups_Achieving_innovation_excellence_and_disruptive_abili ty (accessed July 1, 2019).

[5] Lopez, Jorge. Types of Innovation. California, June 29, 2015.

[6] Mustopo, Ali. "Integrasi Agama dan Ilmu Pengetahuan." Jurnal Al Afkar, 2017: 84.

[7] White, Stephanie M. "Computer-based systems." Mc Graw Hill, Access > Science, 2014. 